\title{
Presentación en el acto de homenaje de la Universidad de Chile a los Premios Nacionales de Humanidades
}

\author{
PRESENTACIÓN DE ROBERTO TORRETTI
}

Eduardo Carrasco

\begin{abstract}
Sería temerario de mi parte intentar dar aquí en unos pocos minutos una visión completa del itinerario filosófico de Roberto Torretti. Mi elocuencia no da para tanto, pero tampoco mi conocimiento, pues buena parte de las obras que él ha escrito son de una especialización que desborda completamente mis habilidades. Me refiero a aquellas que tratan sobre temas de física y geometría y que exigen un conocimiento acabado de estos temas y de su historia. Por lo tanto, voy a referirme principalmente a lo que sí puedo apreciar y con el resto expondré sucintamente lo que conozco de oídas. Espero que esto sea suficiente para dejar en claro el valor de su obra, pero también el de su persona, a la que me he acercado desde que en 1995 volvió a Chile de su larga estadía en Puerto Rico.
\end{abstract}

Lo primero que quisiera dejar en claro es que el mérito más grande que creo pueda atribuirse a su persona, no está en su impresionante currículo, que podría llenar páginas, sino en un hecho que para algunos podrá parecer poco relevante, pero que para mí es lo esencial. Lo digo sin ambages: Roberto Torretti es filósofo. Todos ustedes saben lo difícil que es definir en qué consiste este adjetivo, pero para situarnos en el punto que deseo poner en relieve, podría afirmar, por ejemplo, que si viviéramos en la época de Diógenes Laercio, Torretti podría perfectamente haber ocupado algunas páginas de su libro, tanto por la validez y profundidad de sus ideas, como por sus características personales, que darían para relatar no pocas anécdotas ilustrativas de su templanza indiscutiblemente filosófica. Se trata de alguien irremediablemente curioso, que ha dedicado toda su vida a responder en forma rigurosa las preguntas que la vida le ha puesto delante, que ha seguido aprendiendo sin descanso los más variados temas que puedan imaginarse, que se caracteriza por ser extremadamente puntilloso en el uso de sus palabras, que posee una buena cuota de orgullo y hasta a veces una cierta excesiva seguridad excusada por su saber preciso y certero, que vive rodeado de libros perfectamente ordenados según sus necesidades de estudioso, que ama la música y la escucha en aparatos de una inverosímil fidelidad, que acostumbra subir a los cielos y quedarse un buen momento en ellos hasta el último acorde, que perfectamente podría caerse a un pozo y ser objeto de burla por una criada tracia, que posee una memoria portentosa que hace que en su cabeza se hayan acumulado muchos más saberes que los necesarios para realizar su labor de profesor y escritor, que enseña lo que sabe con generosidad y disciplina, y que mira la vida con distanciamiento, con sabio escepticismo 
y sin caer en ningún entusiasmo excesivo que lo vaya a desviar de su ruta de pensador. Todo esto, lo repito, no quiere decir otra cosa que Roberto es un filósofo.

Algunos irreflexivamente pensarán que ser filósofo en los tiempos que corren no es gran cosa, y que algo que es más un favor de los dioses que un mérito personal no merece ser tan celebrado. Se equivocan: ser filósofo es recibir de pronto un mandato ineludible y responder a él con responsabilidad "todos los días todo el día" como decía Matta, es decir, ser consecuente con los dones recibidos y trabajar con tesón para que la vocación sea atestiguada con obras. Esto es lo que ha hecho Roberto durante toda su vida. Y para convencerlos, voy a tratar de poner delante de ustedes algunas de ellas. Se darán cuenta de que todo esto que digo no es broma.

Sabemos que Roberto nació en Santiago de Chile el 16 de enero de 1930, esto es, en un rincón del mundo olvidado por la filosofía y desde el que es muy difícil ser reconocido como participante en las ligas mayores de esta disciplina. Por otro lado, en una época en la que además, este paraje estaba bastante poco visitado por la Mnemosine filosófica. Y bien, Roberto hizo la proeza de encaramarse en estas ligas hasta el punto de transformarse en un referente mundial en su especialidad, que es el campo de la historia y de la filosofía de las ciencias. Hay que decir que los científicos son en general bastante celosos y exigentes y que refunfuñan bastante cuando alguien que no viene de sus territorios se mete a dar opiniones y a hacer interpretaciones sobre sus materias. Roberto lo ha hecho con mucha propiedad y la prueba es que ha sido reconocido como miembro de número de la Academie Internationale de Philosophie des Sciences con sede en Bruselas, en 1988, y elegido como miembro del Institut Internationale de Philosophie con sede en Paris, en 1994. La Universidad de Puerto Rico, por su parte, lo nombró Profesor Emérito en el 2001, organizando un Simposio en su honor, y la Universidad de Barcelona le confirió el Doctorado Honoris Causa en el 2005.

Lo que se ha premiado a través de estos reconocimientos públicos son, por cierto, sus numerosas obras. Hagamos un breve inventario de las que nos parecen más importantes agregando algunas notas biográficas:

Partamos por su libro sobre Kant. Recuerdo exactamente la impresión de sorpresa que me causó en algún momento del año 1967 ver sobre la mesa de novedades de la Librería Universitaria el libro muy bien editado de tapas azulinas con el título "Manuel Kant, Estudio sobre los fundamentos de la filosofía crítica". Autor: Roberto Torretti. Debo recordar que en esa época era muy improbable que un chileno publicara un libro de 600 páginas sobre la Crítica de la Razón pura. Sin embargo, ahí estaba. Lo compré de inmediato y pude constatar que se trataba de una obra de primera importancia, que perfectamente podía ponerse al lado, o por encima, de otras obras clásicas sobre el pensador alemán que los estudiantes de esa época leíamos con interés. Boutroux, por ejemplo, tan celebrado en esos años como introducción al kantismo, empalidecía frente a la obra de Torretti, que se transformó de inmediato en lectura obligada para todos nosotros. Fue reeditado años después, y en el 2005 se ha hecho una nueva edición corregida y aumentada y eso demuestra que este libro sigue vigente y me atrevo a afirmar que tendrá todavía una larga vida. La obra trata de los fundamentos de las doctrinas de Kant sobre el espacio y el tiempo y, en una segunda parte, sobre las 
categorías. En una tercera parte se trata el problema de la deducción de las categorías y en una cuarta el tema de la cosa en sí. Es decir, trata los temas fundamentales de la obra sobre la base de una bibliografía impresionante, que permite abrir las puertas del kantismo con entera propiedad.

Torretti había comenzado sus estudios de filosofía en nuestro Departamento, que en esa época formaba parte del Pedagógico y quedaba en la calle Cumming. En el Pedagógico había en esos tiempos algunos buenos profesores, como Luis Oyarzún, en estética, Eugenio González, en sociología, Bogumil Yasinowsky, que enseñaba Historia de la cultura y Filosofía medioeval, Felix Scwartzmann, en filosofía de las ciencias y, después, Jorge Millas, y un curioso profesor Erwin Johann Rusch que era una especie de precursor de varias ideas de Foucault. Probablemente, buscando un complemento más cercano al mundo, como ocurre todavía hoy día, Roberto estudiaba paralelamente la carrera de derecho. Eso explica que cuando se fue a hacer su doctorado a Alemania, aprobado en 1954, su tesis versara sobre Filosofía Política: "La estructura sistemática del pensamiento político de Fichte", trabajo patrocinado por el profesor húngaro Wilhelm Szilasi, amigo de Heidegger.

Esta estadía suya en Alemania fue decisiva en su vida, creo que más que por los estudios realizados allí, por su matrimonio en Freiburg con la que ya era su compañera de vida, Carla Cordua. A partir de ese momento sus vidas se unieron para siempre formando un dúo de pensadores tan ligados uno con el otro, que es una hazaña que el nombre de Carla aparezca recién en la cuarta página de esta reseña biográfica. Y comprendo perfectamente la resolución tomada por la comisión que les otorgó el Premio Nacional de Humanidades cuando se discutía sobre la premiación de uno de ellos. Filosóficamente no se parecen en nada. Personalmente tampoco. Pero ahí los tenemos desde que se encontraron: una unidad indisoluble en la disimilitud. No me entiendan mal, no quiero decir una unidad de contrarios. Unidad indisoluble en la disimilitud se parece bastante a una definición que pudiéramos hacer del amor.

Después de un paso por Chile, donde Roberto enseñó en el Pedagógico de Valparaíso, a fines de 1955 partió a EE.UU. a trabajar en la ONU como traductor y en esa ocupación estuvo hasta que le llegó una invitación para integrarse junto a Carla a la Universidad de Puerto Rico. Vuelve una vez más a Chile en 1961 y se incorpora a la Universidad de Concepción como profesor y Director del Departamento de Filosofía de esa Universidad.

Posteriormente se traslada a Santiago y en 1964 funda el Centro de Estudios Humanísticos de la Facultad de Ciencias Físicas y Matemáticas. La existencia de este Centro, según recuerdo, cambió completamente el mapa de los estudios filosóficos en Chile. La palabra "Centro" es muy adecuada, porque allí se congregó la flor y nata de los filósofos chilenos y muchos intelectuales de nota, como el propio Nicanor Parra, por ejemplo. Como esa Facultad siempre ha tenido dinero, allí se armó una biblioteca que fue la envidia de todos los estudiosos en ese momento, y por supuesto, de todos los filósofos pobretones que éramos nosotros, los de la Facultad de Filosofía. En el Centro se formó un círculo de lectura de la Fenomenología de Hegel que rápidamente transformó en hegelianos a buena parte de los asistentes, que se sentían privilegiados - sin duda 
que lo eran- por estar abordando esa obra con tal grado de seriedad y profundidad. El Centro duró mientras Torretti estuvo a su mando, pero en cuanto él volvió a Puerto Rico, en 1970, entró en una historia de decadencia que creo dura hasta ahora. Me consta que se ha intentado varias veces traer los famosos libros a nuestra biblioteca, pero hasta ahora siguen guardados en la Facultad que los compró.

En Puerto Rico, Torretti se quedó hasta 1995 y allí, además de enseñar, dirigió la revista Diálogos desde 1972, la que se transformó bajo su dirección en un referente protagónico de la filosofía en nuestro continente.

En 1978 se publicó su libro Philosophy of Geometry from Riemann to Poincaré, que es el primer estudio histórico-crítico publicado en inglés sobre ese tema, después del libro de Bertrand Russell, Foundations of Geometry (1897). Este libro, recomendado especialmente para su publicación por el matemático alemán de origen judío Hans Freudenthal, estudia la evolución de los conceptos geométricos después de Kant hasta Poincaré y es el primer tomo de una obra proyectada que se completará más tarde con otros trabajos. Su libro Relativity and Geometry, publicado en 1983, es un análisis conceptual de las teorías de la relatividad de Einstein, y por el rigor con que está escrito ha sido comparado por algunos especialistas, con el que Mach hizo de la teoría de Newton en su libro de 1883, Die Mechanik in ihrer Entwicklung historisch-kritisch dargestellt. El libro Creative Understanding: Philosophical Reflections on Physics, publicado en 1990, puede considerarse como su principal aporte a la filosofía de las ciencias. Este libro acaba de ser editado en una traducción hecha por su autor bajo el título "Inventar para entender". En él se expone la tesis según la cual los conceptos científicos, como cualquier otro concepto, surgen en el curso de la historia y por lo tanto, pueden considerarse como invenciones. Debido a que la tesis se ejemplifica con la experiencia de la física el libro se subtitula Reflexiones filosóficas sobre la física. En 1998 se publica su obra El paraíso de Cantor, que de acuerdo al testimonio del filósofo español Jesús Mosterín "es la obra mejor y más completa que jamás se ha escrito en español sobre los fundamentos y la filosofía de las matemáticas". El libro, a partir de la exposición de la teoría de conjuntos de Cantor, pone a la luz el problema de los fundamentos de las matemáticas y recorre los principales aportes y discusiones que han tenido lugar en ese ámbito en los primeros 30 años del siglo XX, desde el programa de Hilbert de axiomatización de las matemáticas, su evolución, sus cambios y adecuaciones, hasta el giro que tomó el programa con ocasión de la aparición del teorema de incompletitud de Gödel. El libro The Philosophy of Physics, publicado en 1999, resume los conceptos fundamentales en que se asienta el desarrollo de la física y muestra de qué modo la filosofía ha aportado a la evolución de esta ciencia, constituyéndose esta obra además, como una introducción al pensamiento contemporáneo sobre esta materia. En el 2007, se publicó en Chile De Eudoxo a Newton, libro destinado a mostrar las fuentes griegas del pensamiento físico-matemático de Galileo y Newton.

Además de estas obras mayores, Torretti ha recogido sus artículos publicados en diferentes revistas y compilaciones en tres libros de estudios filosóficos. El primero, con los trabajos escritos entre 1957 y 1987 , que tratan de temas muy variados que van desde Descartes y Leibniz hasta Heidegger, Unamuno y Wittgenstein; el segundo, correspondiente a los años 1986 al 2006 que trata sobre problemas generales de filosofía 
de las ciencias, y el tercero correspondiente a los años 2007 al 2009, sobre filosofía de las ciencias y en especial sobre el tema de la gravedad. Una nota que muestra hasta donde llega la minuciosidad de Roberto en sus publicaciones es que el diseño gráfico de sus libros publicados desde su vuelta a Chile en la Editorial de la Universidad Diego Portales está hecho por él mismo. De ese modo ha logrado ganar su batalla en contra de los motes, evitado el terrorífico peligro de los correctores de pruebas. Sus libros van de su computador, directo a la imprenta. Y hasta es autor de un completo alfabeto griego que él mismo diseñó y que ha utilizado en sus ediciones.

Como si todo esto fuera poco, Roberto posee un sorprendente don de lenguas y le gusta leer todo lo que lee en su idioma original. Sabe un montón de idiomas y entre ellos el griego clásico. Ha hecho varias traducciones de tragedias de Sófocles y hace algunos meses acaba de editar una más, Filoctetes. O sea, más que ser honrado con el Premio Nacional, creo que es él quien lo dignifica. El hecho de que haya pasado por aquí en sus primeros pasos hacia la filosofía es un acontecimiento de primera importancia para esta Facultad y para este Departamento. Con ello queda demostrado lo que a algunos pueda parecer un milagro: que es posible que de aquí salgan filósofos y eso es nada menos que justificar nuestra razón de ser. Y que no se me olvide: él es también lo que yo llamo un "ciudadano responsable", esto es, uno que reacciona cada vez que alguna noticia o alguna opinión despierta su conciencia crítica. En esos casos escribe cartas al director de El Mercurio o reacciona con mesura pero con fuerza escribiendo comentarios en la página de Opinión. Sus ideas son liberales, republicanas, detesta las beaterías de todo tipo y defiende los fueros de la cultura y el pensamiento.

No les recomiendo discutir con él sobre metafísica, pero si tienen la sabiduría de dejar el tema de lado, se encontrarán con un magnífico conversador, culto y de una erudición impresionante. En sus palabras encontrarán restablecido el bello y sereno escepticismo de Montaigne. ¿Qué más se puede pedir? Nada más. Por eso nuestro agradecimiento: se merece este homenaje y muchos otros. Pero principalmente el mejor de todos, que consiste en leer su obra y estudiarla con la atención que se merece. Ojalá que estos festejos no nos hagan olvidar lo principal, que es la exigencia que en cuanto filósofos de la Universidad de Chile todos tenemos, de intentar ponernos a su altura como para decir con propiedad y sin ninguna presunción: este es uno de los nuestros.

Muchas gracias 